\title{
Unknown Primary Tumor cN3 TNM Finding v8
}

National Cancer Institute

\section{Source}

National Cancer Institute. Unknown Primary Tumor CN3 TNM Finding v8. NCI Thesaurus. Code C132662.

Unknown primary tumor with metastasis in a cervical lymph node larger than $6 \mathrm{~cm}$ in greatest dimension and ENE(-); or metastasis in any cervical node(s) with clinically overt $\operatorname{ENE}(+)(E N E c)$. ENEc is defined as invasion of skin, infiltration of musculature, dense tethering or fixation to adjacent structures, or cranial nerve, brachial plexus, sympathetic trunk, or phrenic nerve invasion with dysfunction. (from AJCC 8th Ed.) 